\title{
Design of a modular locomotion system for autonomous mobile robots
}

\author{
Iosif-Adrian Maroșan ${ }^{1, *}$, and George Constantin ${ }^{2}$ \\ ${ }^{1}$ University "Lucian Blaga" of Sibiu, Department of Industrial Machines and Equipment, Emil Cioran \\ 4, Sibiu, Romania \\ ${ }^{2}$ University "Politehnica" of Bucharest, Robots and Manufacturing Systems Department, Splaiul \\ Independentei 313, Sector 6, 060042, Bucharest, Romania
}

\begin{abstract}
Autonomous mobile robots are becoming more popular today and are successfully integrated into many civil and industrial projects. In the industrial sectors flexibility and modularity have an important role, so the production can be diversified and achieved with low costs. This paper presents the conceptual and functional design of a modular locomotion system for an autonomous mobile platform that can be configured according to the needs of the industrial environment it serves. The architecture of the locomotion system is based on a spring suspension system and three types of wheels: conventional wheels, omnidirectional wheels and mechanum wheels. The calculations for the chosen suspension system are presented, which ensure the contact with the ground for each type of wheel and the resignation calculations for the engine that will drive the wheel. Finally, some variants of configurations are presented that can be made on an autonomous mobile platform with these modules.
\end{abstract}

\section{Introduction}

Research in the field of mobile robots has expanded rapidly, due to their many advantages. Today it is no longer a novelty that mobile robots are used in various industrial sectors, in agriculture, in logistics or in the military [1]. This high degree of use leads to the next step of the new industrial revolution in which the capacity of robots will increase so much that it will be able to imitate any human action [2]. Depending on the applications, maneuverability and locomotion systems, different types of mobile robots have been designed [3-4]. Due to the great diversity of applications in which mobile robots can be used, there is a need to develop a robotic system as a basic mobile platform that can be integrated into various applications in industry and other economic sectors [5]. The main purpose of this research is to design and develop a concept of modular locomotion for mobile robots that can serve the industrial sector. The stages of realization of this modular locomotion system with wheels, include mechanical design, suspension system design, suspension calculations and suspension system verification and sizing calculations for choosing the engine that will drive the wheel. For the construction of mobile robots, several types of locomotion systems can be used, such as robots with conventional wheels, tracks, mechanic wheels, omnidirectional wheels, or

* Corresponding author: adrian.marosan@ulbsibiu.ro 
legs, depending on the need and the applications in which they are used. The most widespread in the industry is the robots with conventional wheels that offer them mobility and high speed but low maneuverability. There are also omnidirectional robots that use different wheels, such as omni wheels, mecanum wheels, steering wheels, and omnidirectional rails [5]. Modular robotics is a topical approach in which several homogeneous or heterogeneous robot modules are assembled according to the requirements, with high flexibility and low costs. Modular robotics aims to provide solutions to various limitations of conventional robots that have been developed for only one type of application [6]. Modularity-the mobile platform can be assembled or disassembled easily by staff who do not need special training due to the design and simple mechanisms used in the construction of individual modules. Reconfigurability - the reconfigurability feature of a modular robot can be attributed to an individual robot as a capability due to its design features. Modular robots are usually equipped with docking mechanisms to join and separate from other robots while forming coordinated structures [6]. Next, it presents a modular design for a locomotion system with different types of wheels and the possibilities of configuring a mobile platform with these types of modules.

\section{Mechanical design of the modular locomotion system}

Figure 1 shows an isometric view of the designed locomotion system where the main components of the whole are described. The system was designed to be used in the construction of a mobile robotic platform that will serve an industrial area. For these reasons, a connection system of the module on the motherboard was designed with the help of two centering pins and a single screw. This system ensures a fast centering and an increased rigidity but also an easy assembly or disassembly. The suspension system ensures that the wheels are in constant contact with the ground regardless of the surface on which the robot will run. The wheel clamp was designed for three types of wheels, conventional wheels, mechanum and omnidirectional all with an outer diameter of $100 \mathrm{~mm}$. A DC motor with brushes was chosen for driving the wheels together with a planetary reducer that offers a high torque, but also a low acquisition cost $[9,10]$.

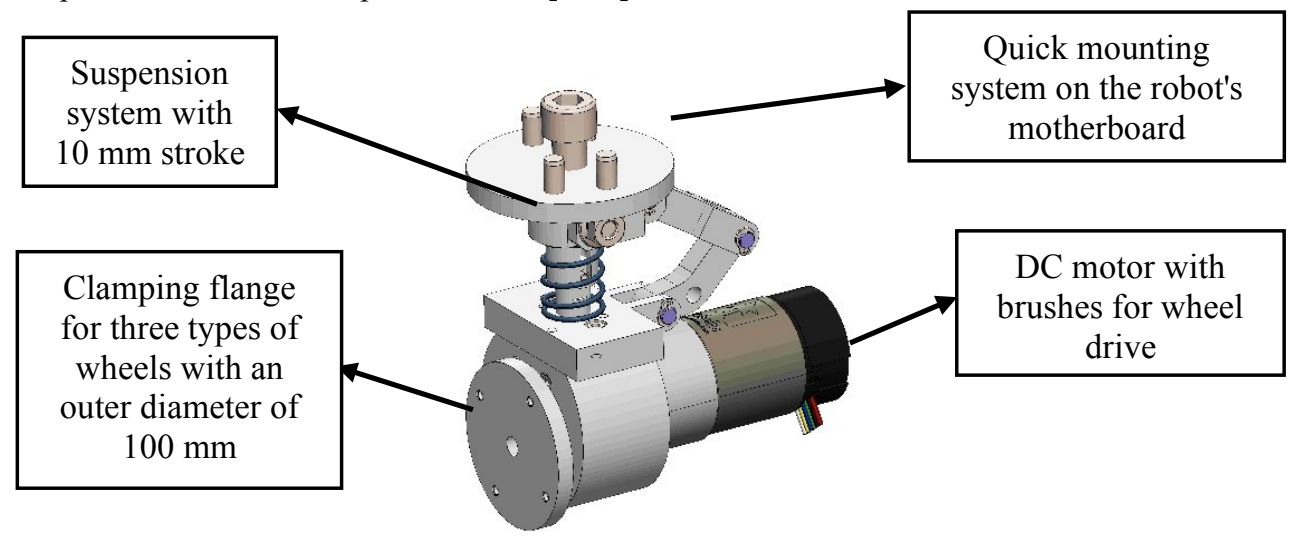

Fig. 1. Modular locomotion system CAD. 


\section{Design and sizing of the spring suspension system}

The main role of the suspension is to ensure the elastic connection between the chassis, body or directly with the robot wheels. Elimination of vibrations that can be transmitted by wheels, prevents the occurrence of damage to components caused by inertial forces. If the suspension system meets all these requirements, another objective to be achieved is that the robot can reach high speeds and have vibrations equal to or less than a vehicle without suspension $[7,8]$. Another important role of the suspension system is to ensure the contact of the wheels on the running surface of the robot at variable speeds and at changes in the surface of the ground on which the robot moves. The suspension system shown in Fig2. It is like the systems used on landing planes for small aircraft. This system is based on the structure of a simple mechanism to be designed and realized with low financial efforts, but which ensures a high rigidity and reliability.

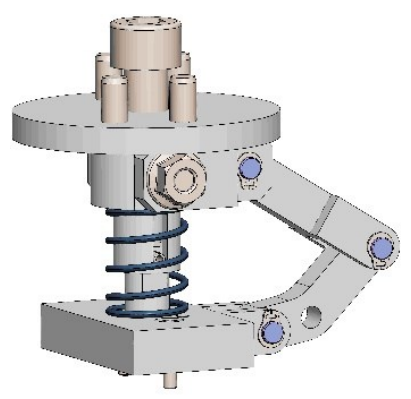

Fig. 2. Modular locomotion suspension system

\subsection{Calculation of sizing and verification of the suspension mechanism}

This type of mechanism is similar to the connecting rod-crank mechanism in Fig. 3 which transforms the rotational movement of the element 1 into a translational movement of the element 3 or vice versa.

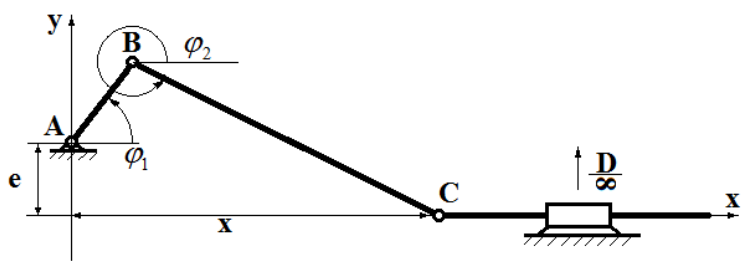

Fig. 3. The classic connecting rod-crank system

The determination of the state of motion of point $\mathrm{C}$ can be determined by the vector equation corresponding to the polygonal account $\mathrm{ABC}$ :

$$
\bar{l}_{A B}+\bar{l}_{B C}+\bar{l}_{A C}=0 \text {. }
$$

If it is projected on the axes it results:

$$
\begin{gathered}
\left\{\begin{array}{c}
O_{x}: l_{A B} \cos \varphi_{1}+l_{B C} \cos \varphi_{2}-x=0 \\
O_{y}: l_{A B} \cos \varphi_{1}-l_{B C} \cos \varphi_{2}+e=0
\end{array}\right. \\
\sin \varphi_{2}=\frac{e}{l_{B C}}+\frac{l_{A B}}{l_{B C}} \sin \varphi_{1}=k+\lambda \sin \varphi_{1}
\end{gathered}
$$


where:

$$
\lambda=\frac{l_{A B}}{l_{B C}} .
$$

Represents the ratio between the length of the crank and the connecting rod, the usual values are between 0.2 and 0.33 :

$$
k=\frac{e}{l_{B C}} .
$$

Represents the relative eccentricity that usually has values between 0 and 0.15 . To determine the value of $\mathrm{x}$ we know that: $\varphi 1<1, \mathrm{k}<\lambda$ and $\lambda<1 / 3$ only the first two terms of the binomial series are retained, resulting in the relation:

$$
x=l_{A B}\left[\cos \varphi_{1}+\frac{1}{\lambda}-\frac{1}{2 \lambda}\left(k+\lambda \sin \varphi_{1}\right)^{2}\right] .
$$



Fig. 4. Suspension system designed

When designing the suspension system, this mathematical relationship was considered, and continued in Fig. 4, the designed system and the dimensions obtained are presented. In this case we will have the following values:

$$
\mathrm{l}_{\mathrm{AB}}=12 ; \quad \mathrm{l}_{\mathrm{BC}}=38 ; \quad \mathrm{x}=37.5 ; \quad \mathrm{e}=5.25 ; \quad \varphi_{1}=79.85^{\circ} ; \quad \varphi_{2}=302.01^{\circ} \text {. }
$$

According to relation (4) the ratio between the length of the crank and that of the connecting rod, must have the usual values between 0.2 and 0.33 .

$$
\lambda=\frac{\mathrm{l}_{\mathrm{AB}}}{\mathrm{l}_{\mathrm{BC}}}=\frac{12}{38}=0.315 \text {. }
$$

According to relation (5) the relative eccentricity usually must have values between 0 and 0.15

$$
k=\frac{e}{l_{B C}}=\frac{5.25}{37.5}=0.14
$$

According to relation (7) the correct choice is validated for the dimensions of the connecting rod and the crank as well as the angles in which it works for a value of the length of the AC

$$
\begin{gathered}
x=l_{A B}\left[\cos \varphi_{1}+\frac{1}{\lambda}-\frac{1}{2 \lambda}\left(k+\lambda \sin \varphi_{1}\right)^{2}\right]=12\left[\cos 79.85+\frac{1}{0.315}-\frac{1}{2 * 0.315}(0.14+\right. \\
\left.0,315 \sin 79.85)^{2}\right]==12[0.176+3.17-1.58 * 0.202]=12(0.176+3,17-0.22)= \\
12 * 3.126=37.51 .
\end{gathered}
$$




\subsection{Spring size for the guide system}

To dimension the spring that will ensure the functionality of the suspension system, two important characteristics were considered, namely the weight force that will compress the spring, the spring constant and the maximum spring compression stroke. The input data for choosing the type of spring required are the following: Maximum stroke of the system: 10 $\mathrm{mm}$, Inner diameter $15 \mathrm{~mm}$, Maximum force in static use $40.73 \mathrm{~N}$. Knowing the finding of the spring as $\mathrm{R}=2.57 \mathrm{~N} / \mathrm{mm}$ it can be deduced that the spring compressed on the $5 \mathrm{~mm}$ stroke will be able to withstand a force of $52.85 \mathrm{~N}$, and when the spring will compress on the entire stroke of $10 \mathrm{~mm}$ the force developed by will be $66.43 \mathrm{~N}$. Starting from these data we chose the design of the spring in Fig. 5, and all the characteristics of the spring are presented in table 1 .

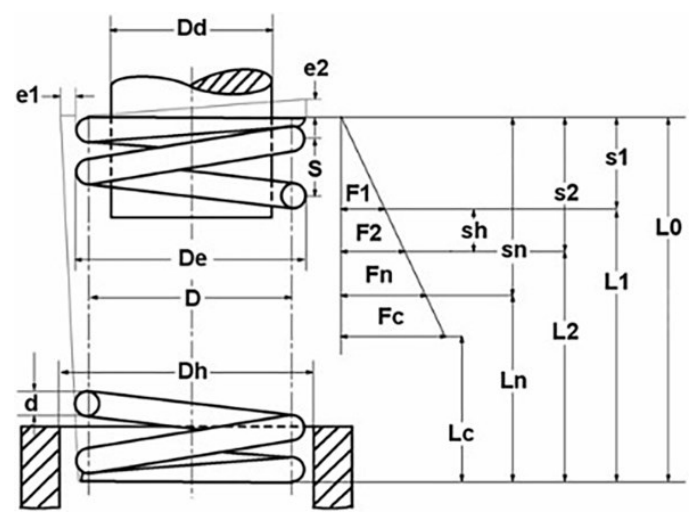

Fig. 5. Compression spring

Table 1. Compression spring features.

\begin{tabular}{|c|c|c|c|}
\hline $\begin{array}{c}\text { Formula } \\
\text { symbols }\end{array}$ & Value & Unit & Description \\
\hline $\mathrm{d}$ & 1.5 & $\mathrm{~mm}$ & Wire diameter \\
\hline $\mathrm{D}$ & 17 & $\mathrm{~mm}$ & Mean coil diameter \\
\hline $\mathrm{De}$ & 18,50 & $\mathrm{~mm}$ & maximum diameter of mandrel \\
\hline $\mathrm{Dd}$ & 14.7 & $\mathrm{~mm}$ & maximum force in static use \\
\hline $\mathrm{Fn}$ & 40,74 & $\mathrm{~N}$ & Maximum spring deflection in static use \\
\hline $\mathrm{sn}$ & 15.81 & $\mathrm{~mm}$ & unstressed spring length \\
\hline $\mathrm{L} 0$ & 25.6 & $\mathrm{~mm}$ & Spring rate \\
\hline $\mathrm{R}$ & 2.576 & $\mathrm{~N} / \mathrm{mm}$ & \\
\hline
\end{tabular}




\section{Drive motor sizing}

In order to set in motion a mobile robotic platform, the mode of locomotion must be able to overcome the frictional forces between the wheels and the supporting surface on which it moves, the inertia forces, but also the frictional forces inside the electrical motor. If the robot moves on a sloping surface, its weight force will also be considered. To obtain a constant speed of the robot, it is necessary for the motors to develop a torque that exceeds the resistive moment from its axis. If the torque required to travel is too small, the robot will not move, and if the electrical motor is kept powered, there is a risk of their failure. The input data considered are the following:

- Total weight of the module: $2.5 \mathrm{~kg}$.

- Maximum weight force per module: $67 \mathrm{~N}$.

- Wheel diameter: $100 \mathrm{~mm}$; Maximum speed: $0.4 \mathrm{~m} / \mathrm{s}$.

- Maximum acceleration: $1 \mathrm{~m} / \mathrm{s} 2$.

\subsection{Determining the forces acting on the mode for a horizontal movement of the mobile robotic platform}

Determining the moment required for the robot to move: Frictional force

$\mathrm{N}$ - represents the normal force at the surface.

$$
\mathrm{F}_{\mathrm{f}}=\mu \mathrm{N}[\mathrm{N}] \text {, }
$$

$\mu$-represents the coefficient of friction and has a value approximately equal to 0.7 .

$$
\mathrm{N}=\mathrm{G}=\mathrm{mg}[\mathrm{N}] \text {. }
$$

$\mathrm{m}$ - represents the total mass of the module which is approximately $2.5 \mathrm{Kg}$.

$\mathrm{g}$ - represents the gravitational acceleration which has the value $9.81 \mathrm{~m} / \mathrm{s}^{2}$.

$F_{t m}-$ Maximum weight force on the module: $67 \mathrm{~N}$.

In view of the above, the friction force has the following form:

$$
\mathrm{F}_{\mathrm{f}}=\left[(\mathrm{m} \cdot \mathrm{g})+\mathrm{F}_{\mathrm{tm}}\right] \cdot \mu[\mathrm{N}]=[(2.5 \cdot 9.81)+67] \cdot 0.7=64[\mathrm{~N}]
$$

The force of inertia

$$
\mathrm{F}_{\mathrm{i}}=\mathrm{ma}[\mathrm{N}]=(2.5+6.8) \cdot 1=9.3[N],
$$

a - represents the maximum acceleration that the robot can reach, in our case it takes the value of $1\left[\mathrm{~m} / \mathrm{s}^{2}\right]$.

After determining the resistance forces, calculate the traction force required to move the robot:

The tensile force Ft is equal to the sum of the inertial force and the frictional force is thus equal to:

$$
\mathrm{Ft} \geq \mathrm{F}_{\mathrm{f}}+\mathrm{F}_{\mathrm{i}} \geq 64+9.3=73.3[\mathrm{~N}] \text {. }
$$

The time required to move the robot exerted by the motor shaft to a wheel is:

$$
\mathrm{M}_{\mathrm{m}}=\mathrm{F}_{\mathrm{t}} \cdot \mathrm{r}=73.3 \cdot 0.05=3.6[\mathrm{~N} \cdot \mathrm{m}] \text {, }
$$

$\mathrm{M}_{\mathrm{m}}$ - represents the motor moment.

$\mathrm{r}$ - wheel radius equal to $50 \mathrm{~mm}$.

The angular velocity of the engine is determined by the following expression and has a speed limit of $0.4[\mathrm{~m} / \mathrm{s}]$ :

$$
\omega=\frac{v}{r}[\mathrm{rad} / \mathrm{s}]=\frac{0,4}{0,05}=8[\mathrm{rad} / \mathrm{s}] .
$$

The speed of the electric motor is given by the following expression:

$$
\mathrm{n}=\frac{\omega \cdot 30}{\pi} \quad[\mathrm{rot} / \mathrm{min}]=\frac{8 \cdot 30}{3,14}=76,43[\mathrm{rot} / \mathrm{min}]
$$

Power required by the electric motor:

$$
\mathrm{P}=\mathrm{M}_{\mathrm{m}} \omega[\mathrm{W}]=3.6 \cdot 8=28.8[\mathrm{~W}] \text {. }
$$


Following the sizing calculations performed to be able to reach the parameters from the input data, the use of a direct current electric motor shown in Fig. 6 with the characteristics presented in table 2 was chosen.

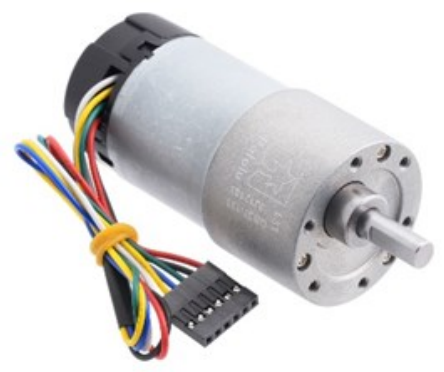

Fig. 6. Motor 37Dx73L Pololu 131:1

Table 2. Main features motor 37Dx73L Pololu 131: 1

\begin{tabular}{|c|c|}
\hline Name & Value \\
\hline Size: & $\begin{array}{c}37 \mathrm{D} \times 72.5 \mathrm{~L} \\
\mathrm{~mm}\end{array}$ \\
\hline Weight: & $210 \mathrm{~g}$ \\
\hline Shaft diameter: & $6 \mathrm{~mm}$ \\
\hline Voltage & $12 \mathrm{~V}$ \\
\hline Stall current & $5.5 \mathrm{~A}$ \\
\hline No-load speed & $76 \mathrm{rpm}$ \\
\hline Stall torque & $4.6 \mathrm{Nm}$ \\
\hline
\end{tabular}

\section{Results and conclusions}

Following the resignation and verification calculations of the modular locomotion system, a set of parameters of this system is obtained. These parameters can be used in the realization of several variants of mobile robotic platforms with different characteristics. In industrial sectors this is a great advantage because the configuration of the mobile robot can be flexible depending on the type of production where it is integrated or the tasks that the robot must perform. Due to these flexibilities, significant costs can be reduced, time is saved and there is also an impact on the environment due to the fact that the robot's chassis remains the same all the time, which leads to reduced mechanical processing, but also fewer electronic components purchased.

Table 3. The main features of the modular locomotion system

\begin{tabular}{|c|c|}
\hline Types of wheels that can be used & $\begin{array}{c}\text { conventional wheel, } \\
\text { mecanum wheel, } \\
\text { omnidirectional wheel }\end{array}$ \\
\hline Wheel diameter & $100 \mathrm{~mm}$ \\
\hline Suspension stroke & $10 \mathrm{~mm}$ \\
\hline Clamping systems & $\begin{array}{c}\text { Flange } \varnothing 60 \mathrm{~mm}, \text { fixing pins } \varnothing 6, \\
\text { grip M10 }\end{array}$ \\
\hline Overall dimensions L $\mathbf{x}$ W $\mathbf{x}$ H & $155 \mathrm{~mm} \times 100 \mathrm{~mm} \times 133 \mathrm{~mm}$ \\
\hline $\begin{array}{c}\text { The maximum torque developed by } \\
\text { the module }\end{array}$ & $4 \mathrm{Nm}$ \\
\hline
\end{tabular}




\begin{tabular}{|c|c|}
\hline Maximum speed reached & $0,4 \mathrm{~m} / \mathrm{s} ;$ \\
\hline Maximum acceleration & $1 \mathrm{~m} / \mathrm{s} 2 ;$ \\
\hline Load on the module & $5 \mathrm{~kg}$ \\
\hline Own weight & $\sim 2 \mathrm{~kg}$ \\
\hline Motor supply voltage & $12 \mathrm{~V}$ \\
\hline Electric power max. & $66 \mathrm{~W}$ \\
\hline
\end{tabular}

Table 3 presents the main characteristics of the modular locomotion system resulting from the study and mechanical design. With the help of these parameters a series of possible configurations of robotic mobile platforms with this type of system are obtained. These can be:

- robotic mobile platforms with two conventional wheels, these having an increased mobility and a load capacity of maximum $10 \mathrm{~kg}$.

- four-wheeled robotic mobile platforms, this type of platform is commonly used in robotic applications that require high maneuverability, the maximum load with this configuration is a maximum of $20 \mathrm{~kg}$.

- $\quad$ six-wheel drive robotic mobile platforms, this type of platform, is intended for applications where there is a need to transport large masses but also where high maneuverability is needed, this configuration allows a maximum load of $30 \mathrm{~kg}$.

- robotic mobile platforms with four omni wheels that allow the robot to move in all directions, without the need to rotate it around the vertical axis, the maximum load for this configuration is a maximum of $20 \mathrm{~kg}$.

Future research directions are directed towards the realization of several tests with all types of possible configurations in which to observe mobility, maneuverability, and positioning accuracy. Also, research will be carried out on the energy side and the current consumption will be monitored for each type of configuration. Following these studies, new parameters will be obtained for this type of modular locomotion system.

\section{References}

1. A. Bârsan, ACTA Univ. Cibiniensis Tech. Ser. 71, 14-20, (2020)

2. M. Crenganis, O. Bologa, 143-8 (2015)

3. H. Taheri, C.X. Zhao, Mechanism and Machine Theory, 153, (2020)

4. R. E. Breaz, S. G. Racz, MTeM - AMaTUC 2017, Using the modern CNC controllers capabilities for estimatig the machining forces during the milling process, (Cluj-Napoca, Romania, 2017)

5. M. Sharifi, M. S. Young, X. Q. Chen, D. Clucas, C. Pretty, Cogent Eng. 3, (2016)

6. CH. S. Sankhar Reddy, Abhimanyu, R. Godiyal, T. Zodage, T. Rane, Journal of Intelligent \& Robotic Systems 101 (2021)

7. G.P. Rusu, M.O. Popp, A. Bârsan, M. Oleksik, ACTA Univ. Cibiniensis Tech. Ser. 70, 43-7, (2019)

8. M. Crenganis, M. Tera, C. Biris, C. Girjob, ITQM 2019, Dynamic Analysis of a 7 DOF Robot Using Fuzzy Logic for Inverse Kinematics Problem, (Granada, Spain, 2019)

9. O. Bologa, RE. Breaz, SG. Racz, M. Crenganiş, ITQM 2016, Using the Analytic Hierarchy Process (AHP) in evaluating the decision of moving to a manufacturing process based upon continuous 5 axes CNC machine-tools, (Asan, Korea, 2016)

10. M. Crenganis, R. Breaz, G. Racz, O. Bologa, ICARCV 2012, Iverse kinematics of a 7 DOF manipulator using Adaptive Neuro-Fuzzy Inference Systems, (Guangzhou, China, 2012) 